our contract we have no defence. A contract incorporating the memorandum principles would cover for this extra workload.

A medical assistant doing my work would be entitled to 22 overtime sessions (more under the new proposals) per month-that is, his pay plus £297 per month. Thus half way up the increment scale his salary will be over the top consultant pay. It is quite easy for a senior registrar to be earning from the N.H.S. more pay than a young consultant.

There is, in the periphery, a majority of S.H.M.O.'s and consultants who are proud of the N.H.S. The pity of it is that they either lack a voice or their voice is not heard. What brain conceived that a nineeleventh part-time consultant should spend substantially the whole of his time on his N.H.S. work and at the same time if he receives a merit award he will only receive nine-elevenths of it? What brain allowed two consultant anaesthetists in this area to work 36 hours on and 12 hours off for month before it conceded that they needed extra help?

Perhaps if the Regional Hospitals Consultants and Specialist Association, if it can spare the time from sending out fatuous questionnaires, and our representatives on the negotiating committee still dominated by the teaching hospitals and the royal colleges, many of whom will not understand a word of this letter, could get together and emulate their junior colleagues in forming a working committee some justice might ensue.-I am etc.,

Bronglais General Hospital, Aberystwyth

\section{Hospital Services for the Mentally Ill}

SIR,-The Secretary of State's latest document Hospital Services for the Mentally Ill has been described by the National Association for Mental Health as "dangerously superficial" and less elegantly "wishy washy." For those of us working in the large mental hospitals the aims expressed would, by and large, be agreed even though in parts the document is somewhat patronizing. What the Secretary of State fails to tell us is how these admirable goals can be realized over a period of 15 years or so.

Mental hospitals, particularly those serving metropolitan areas, are overcrowded, understaffed, and underestablished in al grades of staff from porters to consultants. For years these hospitals have been underfinanced and only recently has some effort been made to rectify some of the more glaring deficiencies in the fabric of such hospitals. Sir Keith Joseph has been quoted as saying that "the long-stay patient as a breed is going to disappear." Certainly less patients are being relegated to wards where there is no expectation of rehabilitation (except those who are irretrievably demented -but this document specifically excludes the 2sychogeriatric problem), but unless some dramatic new form of treatment emerges for schizophrenia and personality dicorders long-term care will still be needed. Whether this care is in a patient's own home, a hostel, day centre, sheltered workshop, or even sheltered communities (shades of the asylum) more and more trained staff-social workers, doctors, community nurses, psychologists, and occupational therapists-will be needed In the meantime during this "run down" period the mental hospital will need more staff if the existing patients who have been in for many years are to have any chance of rehabilitation and not just discharged to be readmitted or swell the population of prisons and doss houses. The physical standards of the hospitals must be maintained and improved even while the purpose-built district general hospital unit is under construction. It is axiomatic, of course, that there should be an adequate number of day centres, hostels, etc. in the community.

I was pleased to note that a recommendation that teaching hospital units should shoulder full responsibility for an area (paragraph 20). Apart from the "creaming off" process, which has for years been resented by the mental hospital standing behind waiting to catch the teaching unit's rejects, it would give undergraduates chance to see what psychiatry is about However, if we are to give the medical student an adequate training and possibly to hope that he may be recruited eventually to the specialty he surely needs not only a realistic setting for his studies but realistic amount of time spent on them, and possibly the stimulus of an examination. While some medical schools still offer as little as a month in a three-year clinical course, psychiatry will inevitably be regarded as a minor specialty. I am not qualified to comment on the training and recruitment of nurses, occupational therapists, social workers, and psychologists but it seems to me in all these spheres of work we need more and better trained people and the Secretary of State's advice to make more use of volunteers is no substitute.

The problems in this transitional period from the mental hospital to the district general hospital unit will not be solved by the injection of money alone into the service. There will have to be a total reappraisal of the training of the staff required to man it, and fundamental research into the number of staff needed to give the service which will be demanded when patients can no longer be hidden away in mental hospitals and looked after by a skeleton staff.-I am, etc.,

Friern Hospital,

J. J. BRADLEY 1 Department of Health and Social Security. Hospital

\section{G.M.C. Retention Fee}

SIR,-It was with total incredulity that I read your leading article detailing the procedure of the G.M.C. in attempting to increase the retention fee (11 December, $p$. 637).

In common with many others I was of the opinion that the G.M.C. was in breach of contract in the first place for introducing the retention fee, but I paid up because $I$ need to practise to live. Now, however, I am convinced that the hotheads were right, and that we should never have agreed to pay the £2. The Council of the B.M.A. should inform the G.M.C. forthwith that no further increase of retention fee will be tolerated or paid. If the employers wish us to remain on the Register, then let them pay direct to the G.M.C. for the privileges enjoyed by the G.M.C., but not by debiting our salaries.-I am, etc.,

COLIN Flowers

Taunton and Somerset Hospital,

an Branch,

Taunton

\section{Dahlak Blindness}

SIR,-In 1955 Professor Bietti of Rome described a bilateral cystic corneal degeneration among certain men in the Red Sea littora. ${ }^{1} \mathrm{He}$ attributed this to climatic conditions. Ten years later Arnold Freedman of Oxford described a less severe bandshaped keratopathy among Labrador fishermen, again blaming it on climatic conditions. In point of fact in 1937 a young Italian Zanettin, ${ }^{3}$ was the first to note the condition in the Dahlak Islands in the Red Sea, islands now part of Ethiopia.

The Scientific Exploration Society has sent a small team out to assess the ocular health of the islanders. We have surveyed five out of seven inhabited islands, sampling $65 \%$ of the population. Our results indicate that this practically unknown disease (which for convenience may be called Dahlak blindness) affects in some degree or another $50 \%$ of the men and women living on the islands. The prevalence rates of blindness vary very little (at around 4,000 per 100,000). Dahlak blindness accounts roughly for $52 \%$ of all blindness, and cataract for $38 \%$. Trachoma is practically non-existent. Smallpox and measles have not occurred in 40 years. The weanlings are somehow deficient in vitamin A, but exhibit no xerophthalmia. The people are happy and clean. They are fishermen and divers, and it is extraordinary to see that although blind on land they can still dive for trochos shells (from which shirt buttons are made) and hoist the lateen sails. The women live at the waters edge, wading for shells and laying fish traps.

It is not often that a comparatively unknown disease is found so conveniently collected for observation. The corneal changes develop somewhat in the manner described by Freedman, and then advance to the grosser changes described by Bietti.

This work will be written up in detail when the material has been analysed and the study completed.-I am, etc.,

Dahlak Island,

F. C. RODGER

Ethiopia

Bietti, G. B., Guerra, P., and Gaspare, P. F. F. de., Bulletin et memoires de la Société Française d'Ophralmologie, 1955, 68. 101

- Freedman, A., Archives of Ophthalmology, 1965,

Zanettin, G., Archivo Italiano de Scienze Mediche Coloniale e di Parassitologia, 1937, 18, 387.

\section{Medical Treatment of Enlarged Prostate}

SIR,-I expect you will have had many protests about one point in your otherwise helpful leading article on the "Medical Treatment of Enlarged Prostate" (11 December, p. 638). I refer to the assertion that "in any trial of the treatment of enlarged prostates . . . a catheter estimation of the residual urine ... [is] required."

This is wrong. Apart from the well known 